\title{
Study on post harvest treatment of guava (psidium guajava)
}

\author{
Kannan, $\mathbf{K}^{*}$
}

Department of Food Technology, Kongu Engineering College, Perundurai, Erode (TN)

*Email: kannan.saam@gmail.com

\begin{abstract}
Guava (Psidium guajava L.) is a climacteric fruit and it ripens rapidly after harvest and it has short shelf life. Hence the guava fruit can be coated with edible materials to delay the ripening and to extend the storage life. Guava fruit were coated with two different combinations $2 \%$ corn starch along with $2 \%$ neem oil and $2 \%$ rice starch along with $2 \%$ neem oil. The fruits were packed using Low Density Polyethylene material (LDPE). The treated fruits were stored under low temperature condition at $6^{\circ} \mathrm{C}$ and also at ambient condition at $25^{\circ} \mathrm{C}$. The results suggested that the coating with $2 \%$ corn starch along with $2 \%$ neem oil proved most effective in retaining the overall quality as it caused minimum changes in most of the physical and biochemical quality characteristics. In general, all treatments caused significant decrease in physiological loss in weight, fruit firmness, pectin content and total acidity. Fruits stored at ambient condition $\left(25^{\circ} \mathrm{C}\right)$ developed faster ripening, pleasant flavor and over softening on further storage. The optimum temperature for storage of guava fruits was $6^{\circ} \mathrm{C}$ and $90-95 \% \mathrm{RH}$ for maintaining highly acceptable sensory quality. At this temperature the fruits had attractive colour, pleasant flavor and acceptable quality and can be stored up to 5-6 weeks. Application of $2 \%$ neem oil significantly reduced the fruit rot and black spot caused by Pencillium expansum and helped to maintain the stability and cellular integrity.
\end{abstract}

Keywords: Guava, Coating, Shelf life, Edible coating, Starch

Paper cited: Kannan, K. (2016). Study on post harvest treatment of guava (psidium guajava). South Asian Journal of Food Technology and Environment, 2(3\&4): 438-447.

\section{Introduction}

Guava is the fourth most widely grown fruit crop in India. Guava is a climacteric fruit and so when it ripens, it bruises easily and is highly perishable (Singh et al., 2007). Fruits for processing may be harvested by mechanical treeshakers and plastic nets. For fresh marketing and shipping, the fruits must be clipped when full grown but under ripe, and handled with great care. The presence of vitamin $\mathrm{C}$ and other phytonutrients, such as carotenoids, isoflavonoids and polyphenols, in guava has led to it being an effective antioxidant. Storage life of guavas is prolonged at $20^{\circ} \mathrm{C}$ (Augustin and Azizah, 1988), relative humidity of $85 \%$, less than $10 \%$ carbon dioxide, and complete removal of ethylene. But in the case wax coating treatment, the wax is not edible. It is also available very rare and hence it is expensive.

Guavas kept at room temperature are normally overripe. But if wrapped using polyethylene material, the produce will be in good condition for 9 days. In cold storage, fruits wrapped using polyethylene material remains unchanged for more than 12 days. Wrapping checks weight loss and preserves glossiness. Unwrapped guavas, just turned yellow, have kept for 4 weeks in cold storage at $8.33^{\circ}-10^{\circ} \mathrm{C}$ and relative humidity of $85-95 \%$, and were in good condition for 3 days thereafter at room temperature of $76^{\circ}$ to $87^{\circ} \mathrm{C}$ (Singh, 2007). Guava was susceptible to dehydration during storage and weight losses of $20 \%, 14 \%$, were recorded after 8 days of storage at $26^{\circ} \mathrm{C}, 20^{\circ} \mathrm{C}$ respectively. The weight loss from the fruit is 
dependent on both the temperature and duration of storage. The rate of water loss from the fruit was higher at higher temperatures (Hawlader et al., 2004).

Reyes et al., (1995) has reported that storage of guava (Psidium guajava) at $15^{\circ} \mathrm{C}$ delayed deterioration of quarter yellow and half yellow fruit and allowed gradual ripening of mature-green fruit in 11 days. The ripening was delayed most by the lowest temperature $\left(10^{\circ} \mathrm{C}\right)$ for the mature-green fruit, and decreasingly less for the ripened fruit and higher temperatures $\left(20^{\circ} \mathrm{C}\right)$. Titratable acidity (TA) and total soluble solids (TSS) of fruit at mature-green stage were not significantly affected by ethylene treatment. Mahajan et al., (2009) has optimized the storage temperature for guava fruit and also their storage behavior has been studied at optimum temperature. The storage of guava at low temperature for a definite period will increase the shelf life of the produce. The fruits stored at $5^{\circ} \mathrm{C}$ did not ripen and developed skin bronzing after two weeks in storage. Two hundred and sixteen fruit of different stages of ripeness (maturegreen, quarter-yellow and half-yellow) were stored in $10,12.5,15$ and $20^{\circ} \mathrm{C}$. Storage of fruit below $10^{\circ} \mathrm{C}$ cause severe chilling injury symptoms in the form of surface pitting, skin and flesh browning. Singh and Pal (2009) investigated the potential of ionizing radiation for improving physiological response, quality and storage time of fresh guava fruit. Irradiation treatment also retarded the physical and biochemical changes associated with ripening changes can be decreased by exposure of doses to $0.25 \mathrm{kGy}$ at $10^{\circ} \mathrm{C}$. Ionizing radiation treatment helps to improve post harvest life and maintain quality of fresh guava fruit.

Coating with edible materials is one of the preservation techniques can be used for fruits and vegetables. Coating of apple can be done by using the combination of Corn starch and Neem oil, Rice starch and Neem oil, since carnauba wax is expensive. Guava can also be coated with the above combination since guava fruit helps in high retention of acidity. Edible coating can be done in order to reduce the cost of the process and also to delay the ripening changes in guava fruit (Wijewardane and Guleria, 2009). Hence keeping all these views and facts in mind, the present study was envisaged with the following objectives: to coat the guava with the combinations of $2 \%$ Neem oil along with $2 \%$ corn starch and $2 \%$ Neem oil along with $2 \%$ rice starch, to package the fruits with LDPE (Low Density Polyethylene) material and store under two different conditions and to study the storage life of coated guava at regular intervals.

\section{Materials and Methods}

The guava variety used for coating is Psidium guajava simply referred to as Apple Guava were selected for the present study. The fruits were bought from local market as a bulk in Erode (TamilNadu) and has been selected at the colour break stage. The fruit which gets bruised or damaged has been removed. Then they were washed with tap water for the removal of dust, sand, stalks and foreign matters and also dried for the removal of moisture. The fruits have been weighed and considered it as initial weight.

The raw materials used for coating of guava are Corn starch, Rice starch and neem oil to delay the ripening process and to reduce the respiration rate of guava. Initially guava is coated with carnauba wax. Since this wax coating is costly and rarely available it is alternated with starch coating. The Main advantages of starch coating are very cheap, commercially available and do not affect the quality of the produce. Corn starch is the starch of the corn grain. In a cup, half the amount of water and two table spoon of corn flour were mixed and formed as slurry. Then the slurry has been heated by raising the temperature. Then they were continuously stirred to form a thin substance. At $64^{\circ} \mathrm{C}$ the slurry got gelatinized and starch has been obtained. The temperature of the starch has been found using 
thermometer. The starch slurries were started to swell and formed as a gel. The rice grains which has been bought from local market. The powdered flour has been used for preparation of rice starch. The method of preparation of rice starch was similar to corn starch preparation. The starch concentration has been bought to $2 \%$ by mixing $2 \mathrm{gm}$ of starch in $100 \mathrm{ml}$ of water. Then they were mixed by continuously stirring since the starch has good digestibility.

Neem oil has been found easily and commercially. The neem oil for the present study of coating was bought from local market. The neem oil concentration was brought to $2 \%$ by mixing $2 \mathrm{ml}$ of oil in $100 \mathrm{ml}$ of water. It was stirred continuously since oil is not soluble in water. It has been tried by adding two or three drops of surfactants such as detergent solution to solublise the oil with water uniformly. The packaging material used for packing the coated and uncoated guava fruit were Low Density Polyethylene material (LDPE). It has been considered as one of the polyethylene materials protects from harmful ultra violet rays and is water resistant. Fruits are cleaned thoroughly with distilled water and dried at ambient conditions. Fruits were coated with rice starch and corn starch along with neem oil in a different combination by pouring method. The coated guava fruits were packed using LDPE materials. Then fruits were stored at two different storage conditions. The physio-chemical properties of coated guava such as physiological loss in weight, total soluble solids, total sugars, titratable acidity, ascorbic acid and $\mathrm{pH}$ were monitored to study the storage life.

\section{Table 1: Design of experiments for coating of guava}

\begin{tabular}{|l|c|c|c|}
\hline $\mathrm{X}$ & $\mathrm{C} 1$ & $\mathrm{C} 2$ & $\mathrm{C} 3$ \\
\hline S1 & $\mathrm{S} 1 \mathrm{C} 1$ & $\mathrm{~S} 1 \mathrm{C} 2$ & $\mathrm{~S} 1 \mathrm{C} 3$ \\
\hline S2 & $\mathrm{S} 2 \mathrm{C} 1$ & $\mathrm{~S} 2 \mathrm{C} 2$ & $\mathrm{~S} 2 \mathrm{C} 3$ \\
\hline $\begin{array}{l}\text { Storage Conditions S1-Atmospheric Condition }\left(25^{\circ} \mathrm{C}-27^{\circ} \mathrm{C}\right) \\
\text { Coatings }\end{array}$ & $\begin{array}{l}\text { C1-Neem } \text { oil }(2 \%)+\text { rice starch }(2 \%), \text { Refrigerated Condition }\left(6^{\circ} \mathrm{C}\right) \\
\text { C3 -control sample (without coating) }\end{array}$ \\
\end{tabular}

\section{Results and Discussion}

The physicochemical properties includes physiological loss in weight, total sugars, total soluble solids, total acidity, ascorbic acid content and $\mathrm{pH}$ were analyzed for coated fruits that were stored under two different storage conditions at regular intervals.

\section{Physiological loss in Weigh}

During storage, an increase in physiological loss was observed in both the combinations of rice starch and corn starch coating treatments up to 42 days of storage period. In corn starch, the physiological loss in weight was around $2.01 \%$ at $6^{\circ} \mathrm{C}$ and in ambient condition, it was around $2.04 \%$ as shown in Fig. $1 \& 2$. In rice starch coating, the physiological loss was around $2.28 \%$ at $6^{\circ} \mathrm{C}$ and less when compared to ambient condition $\left(25^{\circ} \mathrm{C}\right)$ around $2.35 \%$. The guava fruit without coating has high PLW increased from $0 \%$ to $2.54 \%$ at ambient condition than at refrigerated condition.

\section{Total Soluble Solids}

In the corn starch coating under refrigerated storage, the total soluble solids has been increased to peak value of $9.8 \%$ at the storage period up to 21 days and declined during remaining period. In the treatment of rice starch the soluble solids has been increased to maximum level of $10.5 \%$ at the storage period up to 21 days and reduced further to 5.8 during 28 days (Fig. 2). Increase in total soluble solid is due to the hydrolysis of insoluble polysaccharides into simple sugars and is one of 
the primary substrate for respiration (Hind et al., 2003).

\section{Total Sugars}

The total sugars, like soluble solids were fairly low at harvest stage and increased during storage and reached maximum value and followed by further decline. In this study, the fresh fruits (without coated) has the total sugars maximum up to $10 \%$ during first 14 days at $6^{\circ} \mathrm{C}$ and at ambient condition $25^{\circ} \mathrm{C}$, the total sugars was around $11.9 \%$ for first 7 days and were decayed after 7 days of storage period.
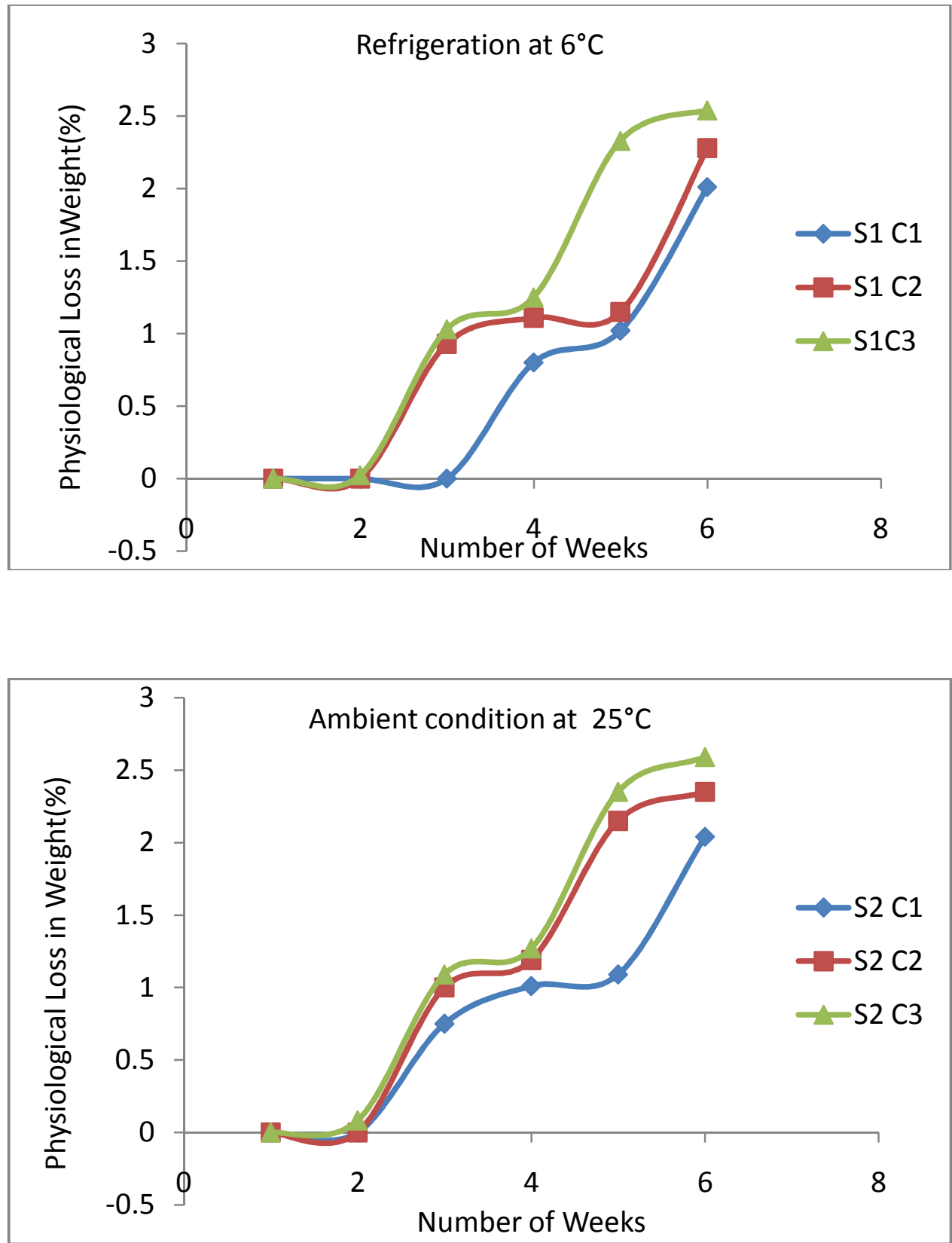

Fig. 1: Changes in physiological loss for treated guava upon storage 

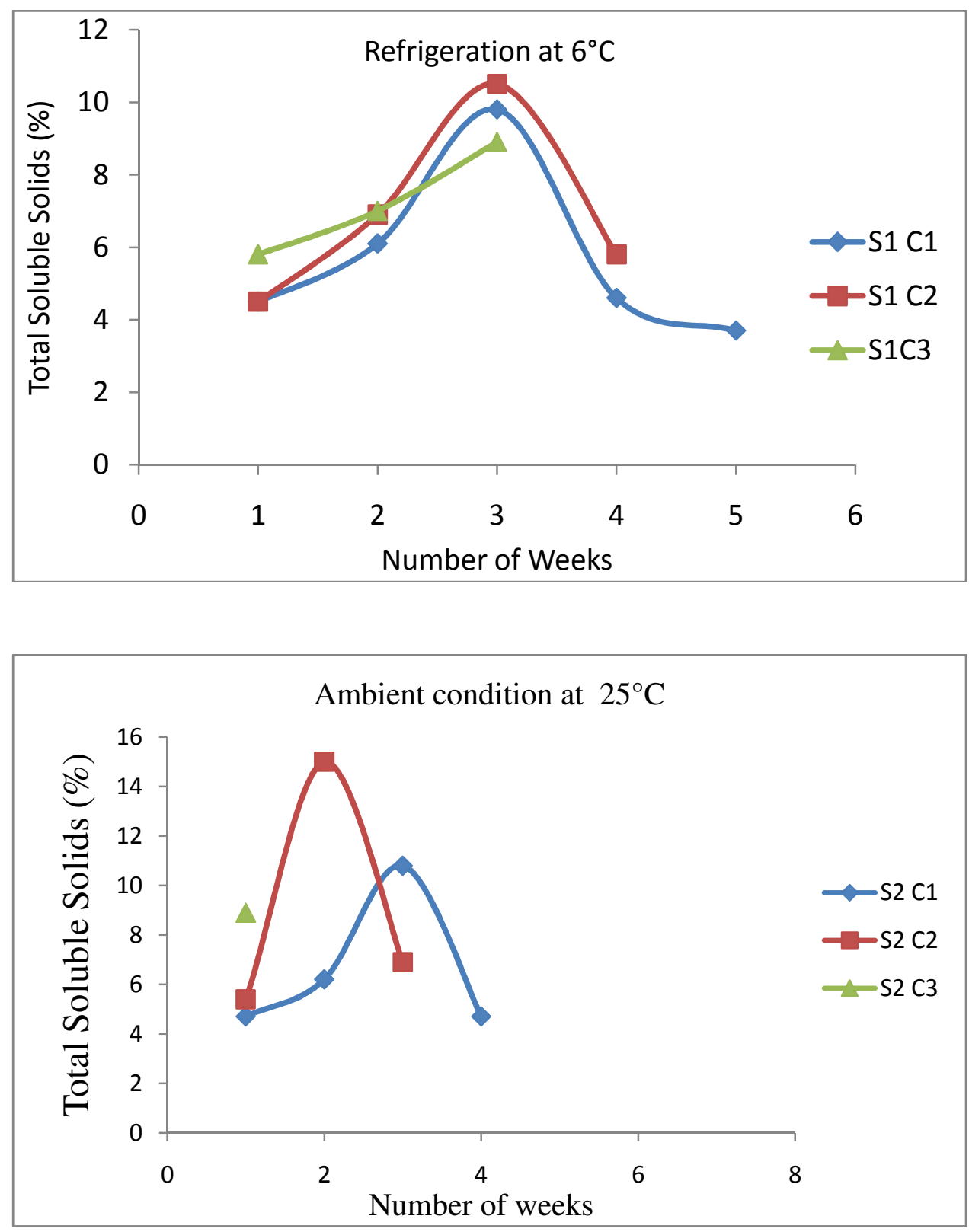

Fig. 2: Changes in total soluble solids for treated guava upon storage

The fruits coated with corn starch at $6^{\circ} \mathrm{C}$ has increased to $6.2 \%$ and reduced to $3.7 \%$ during 42 days of storage period. At ambient condition, the total sugars was increased to $7.4 \%$ and declined to $3.9 \%$ during 28 days of storage period. The fruits coated with rice starch at $6^{\circ} \mathrm{C}$ have showed the increasing trend in total sugars up to $9.3 \%$ and after it was reduced to $3.7 \%$ during 21 days of storage period. At ambient condition $25^{\circ} \mathrm{C}$, the total sugars was increased to $8.5 \%$ and declined to $4.2 \%$ up to 21 days as represented in Fig. 3. 


\section{Total Acidity}

The maximum total acidity of about $50 \%$ was recorded in response to coating with corn starch under refrigerated storage $\left(6^{\circ} \mathrm{C}\right)$ whereas at ambient condition $\left(25^{\circ} \mathrm{C}\right)$ the maximum total acidity has increased from $29.6 \%$ to $44.8 \%$ at 28 days of storage period. An increasing trend from $25 \%$ to $41 \%$ in total acidity for the coating treatment with rice starch was observed at $6^{\circ} \mathrm{C}$ but in the case of ambient condition total acidity was found to increase from $34.3 \%$ to $54.3 \%$ at 21 days of storage period. Singh and Mohammed, (1997) have reported that rice starch coating helps in high retention of acidity. In ambient condition the total acidity was around $78 \%$ at 7 days after which the fruits were decayed are represented in Fig. 4.
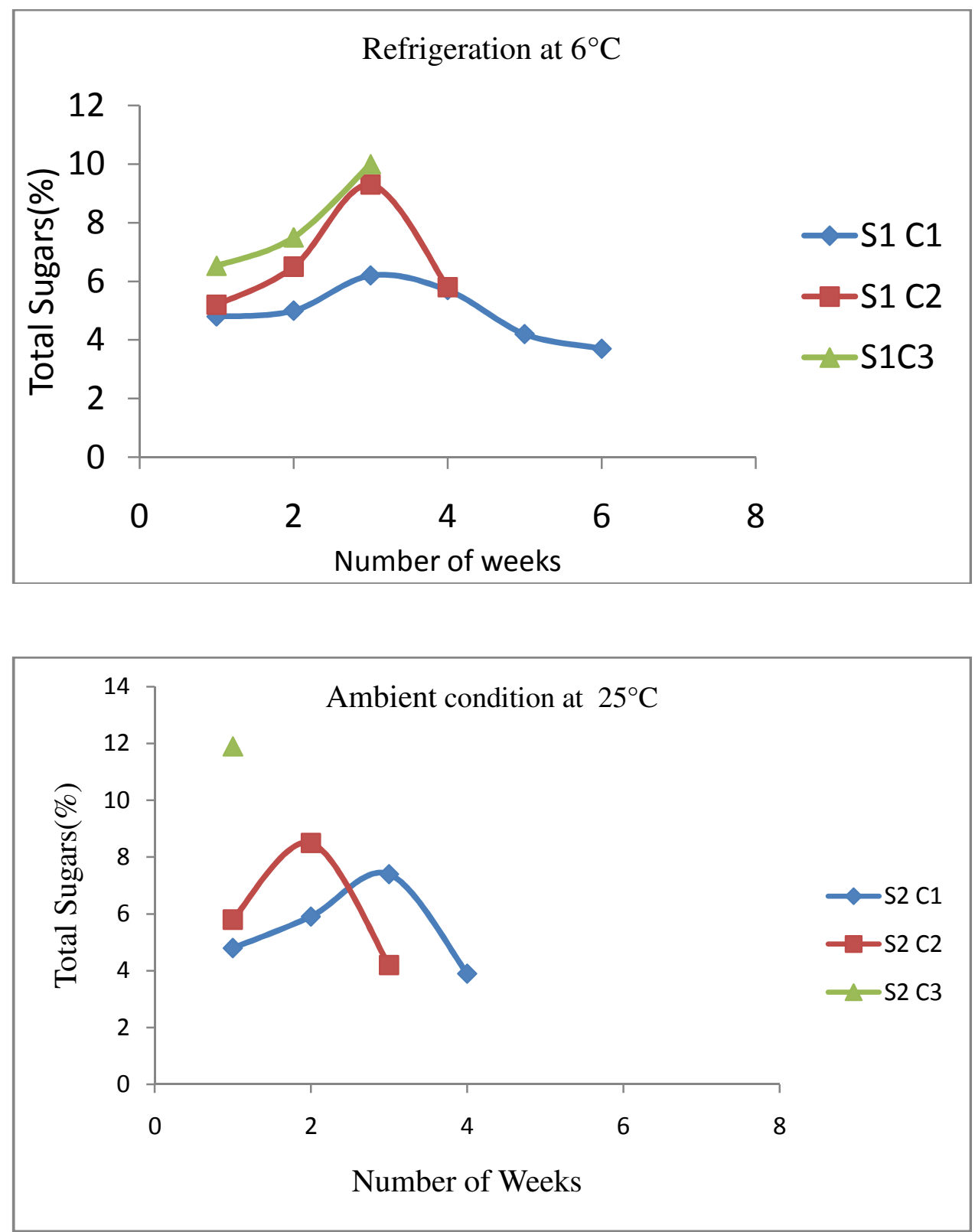

Fig. 3. Changes in total sugars for treated guava upon storage 


\section{Ascorbic Acid Content}

The guava fruits stored under refrigerated storage conditions have more amount of ascorbic acid than it is in ambient condition. Under refrigerated $\left(6^{\circ} \mathrm{C}\right)$ storage and corn starch coating treatment has the maximum value of $180.5(\mathrm{mg} / \mathrm{g})$ which is reduced to 123.5 $(\mathrm{mg} / \mathrm{g})$ at 42 days of storage period. In the treatment rice starch, the ascorbic acid content has the maximum value of $185.9 \%$ and reduced to $115.9 \%$ during 28 days of storage as shown in Fig. 5. Lin et al., (1988) has reported that the fall in ascorbic acid during storage might be due to its oxidation. Ascorbic acid content of fresh weight was maximum at harvest, which has reduced level at the end of the storage period in guava fruit (without coating). After the reduction of AA, the fruits have been found to be decayed and were disposed.
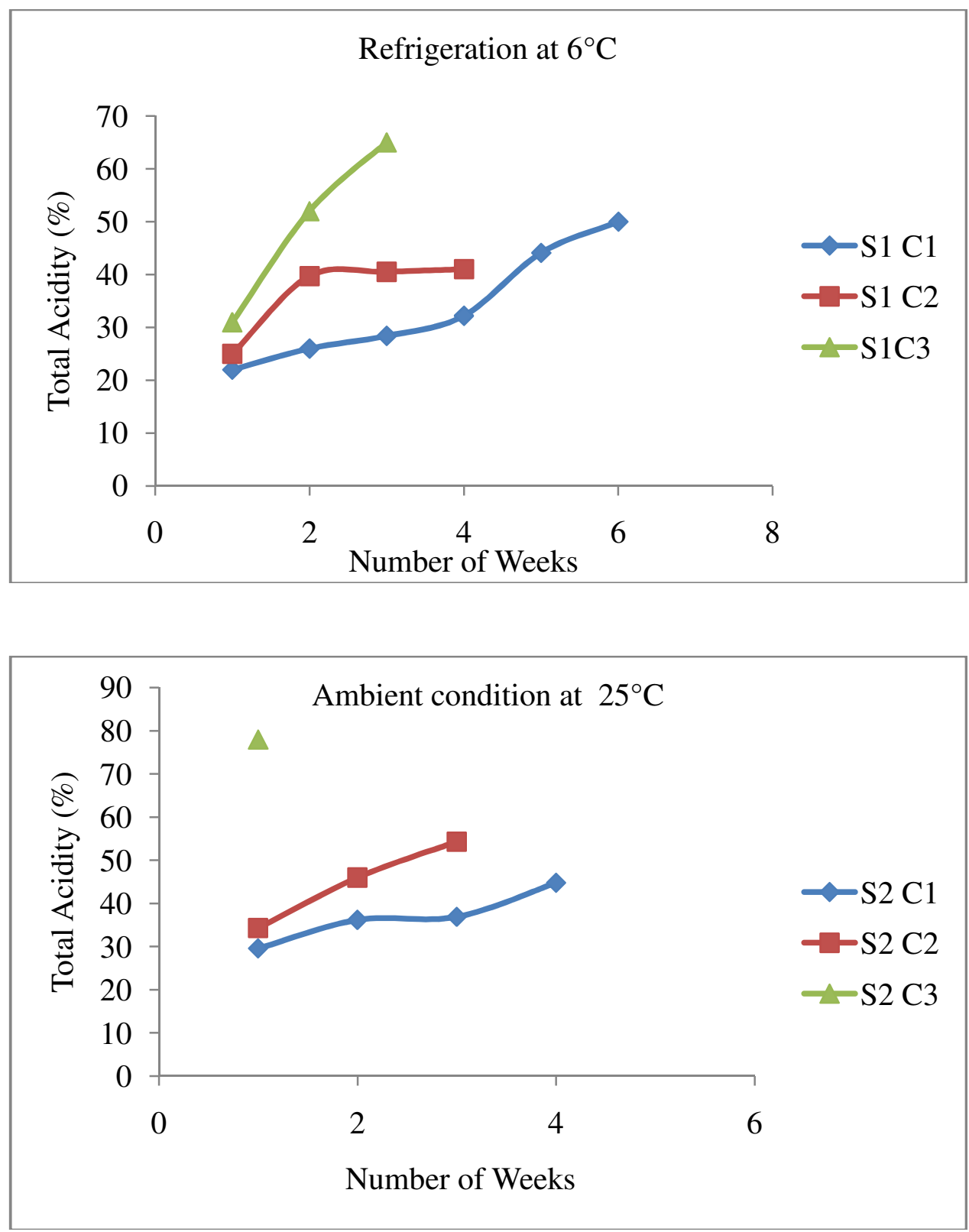

Fig. 4: Changes in total acidity for treated guava upon storage 
pH (Hydrogen ion concentration):

The decrease in $\mathrm{pH}$ was found to be up to 3.7 in corn starch coating treatment under refrigeration storage but in rice starch coating treatment decreased up to 3.9 (Fig. 6). There was a gradual decrease in the level of $\mathrm{pH}$ in both treatments respectively. Wijewardane et al., (2009) have reported that there was a gradual increase in $\mathrm{pH}$ due to decrease in organic acid content.
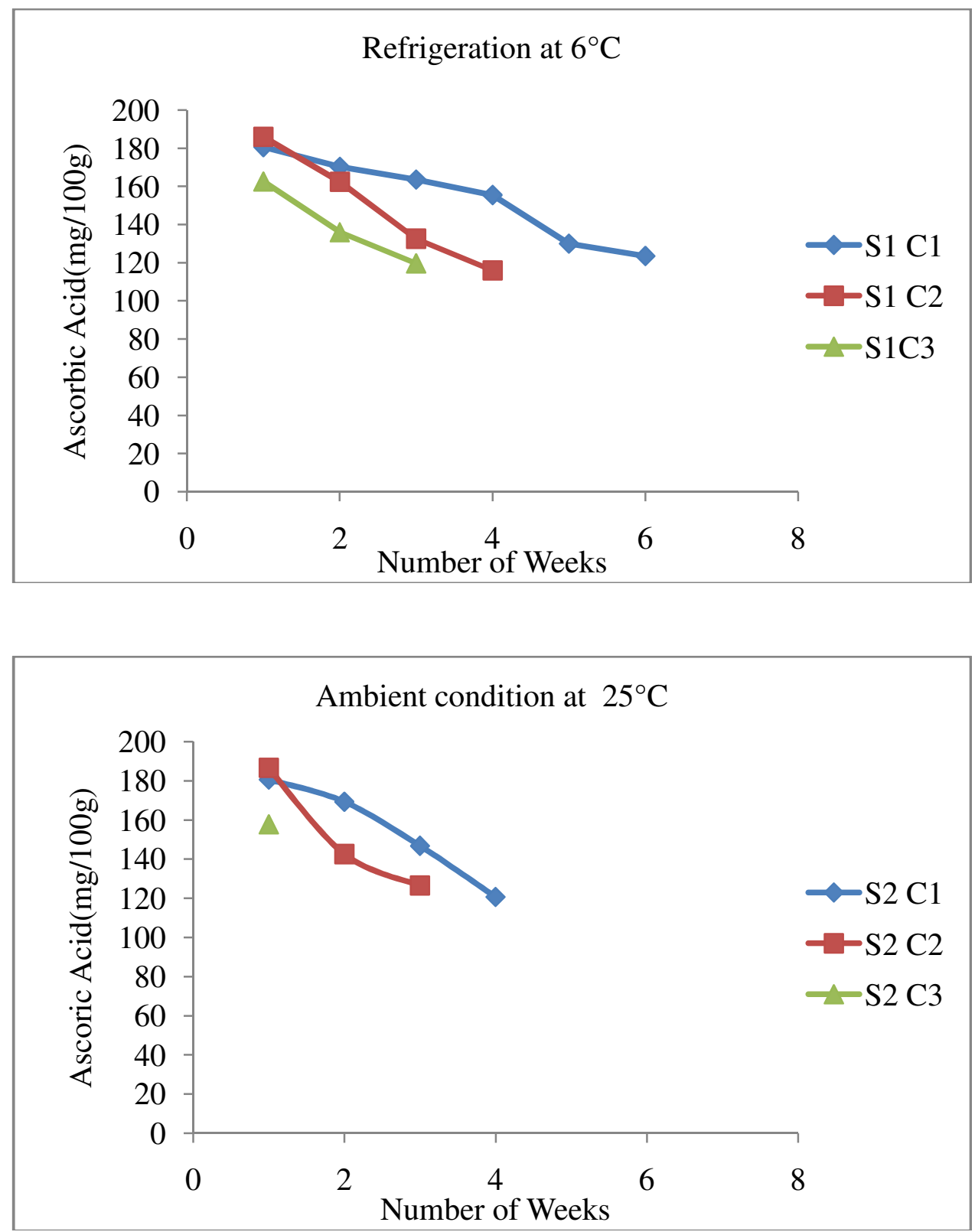

Fig. 5: Changes in ascorbic acid for treated guava upon storage 
Study on post harvest treatment of guava (psidium guajava)
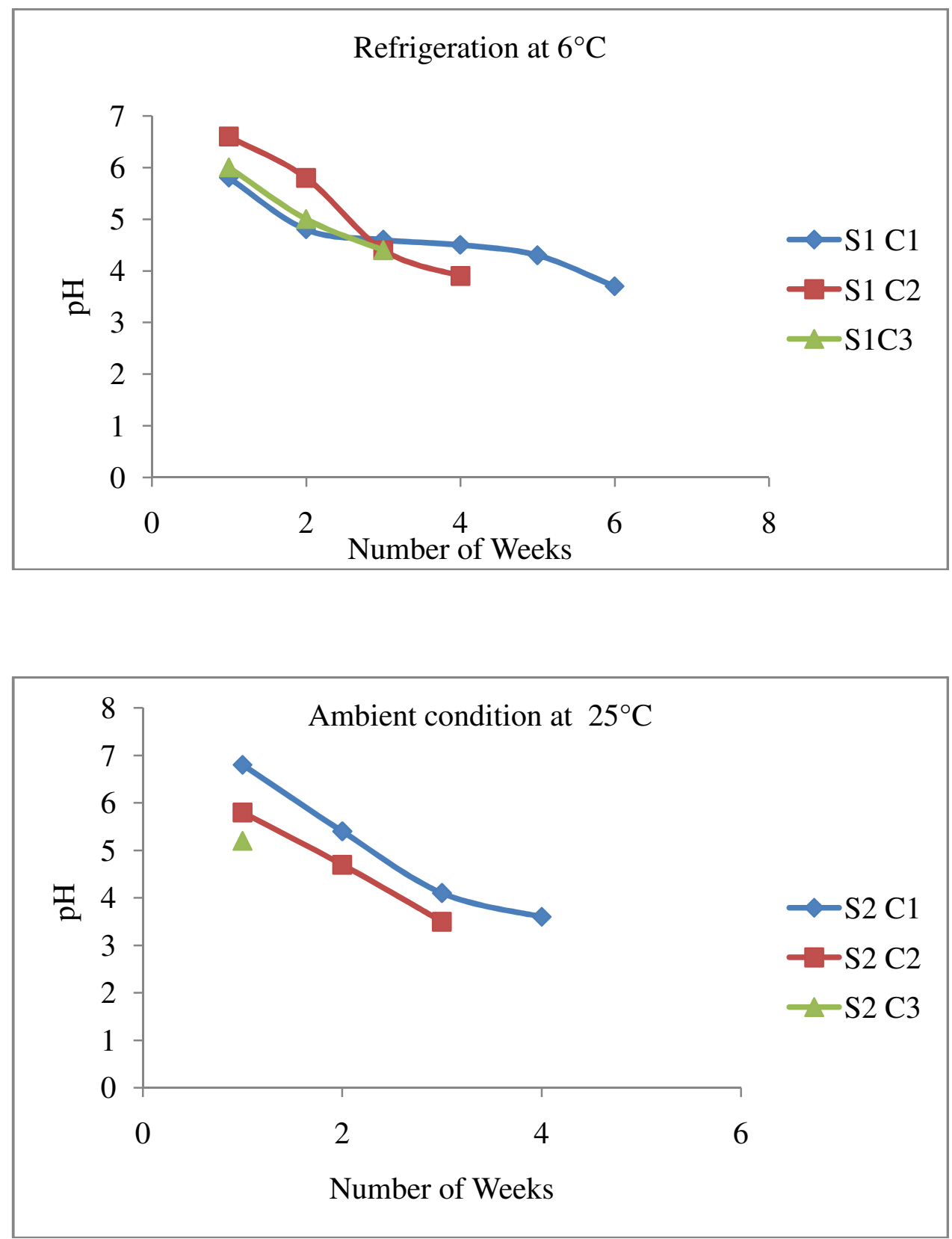

Fig. 6: Changes in pH for treated guava upon storage

\section{Comparative analysis}

It was observed that the fruits stored at refrigerated condition $\left(6^{\circ} \mathrm{C}\right)$ has less increase in physiological loss in weight, total soluble solids, total sugars, titratable acidity and has reduced value in ascorbic acid, and $\mathrm{pH}$ than fruits stored under ambient condition at $25^{\circ} \mathrm{C}$. Normally, guava fruit (without coated) has reduced storage period than the fruits coated with corn starch and rice starch.

Corn starch coating of guava had the shelf life of 42 days when fruits stored at $6^{\circ} \mathrm{C}$ and at ambient condition $25^{\circ} \mathrm{C}$, the shelf life has been lowered to 21 days. Rice starch coated 1 has the storage life of 35 days at $6^{\circ} \mathrm{C}$ and at ambient condition $25^{\circ} \mathrm{C}$, the shelf life has been lowered to 
28 days. The fresh fruits (without coated) has the storage life of 21 days at $6^{\circ} \mathrm{C}$ whereas at ambient condition, it has been reduced to 7 days of storage. The fruits stored under refrigerated condition have more shelf life when compared to the fruits stored under ambient condition.

\section{Conclusion}

This study has been concluded that the best storage condition was refrigeration at $6^{\circ} \mathrm{C}$ since the control sample remained fresh at this temperature till 21 days whereas in rice coating treatment, fruits decayed after 28 days and in corn starch the fruits remained fresh till 42 days of storage period. It has also been concluded that the guava coated with corn starch and neem oil has increased storage period of 42 days than rice starch and neem oil coated fruits which has the storage life of 28 days at $6^{\circ} \mathrm{C}$.

\section{Reference}

1. Augustin, M.A., and Azizah Osman., (1988). Post harvest storage of guava (Psidium guajava, L, Var. Taiwan). Pertanika, 11(1): 45-50.

2. Hawlader, M.N.A., Conrad, O., Perera., and Min Tian (2004). Properties of Modified atmosphere heat pump dried foods. Journal of Food Engineering, 74: 392-401.

3. Hind, A. Bashir., Abu-Bakr, A. and AbuGoukh (2003). Compositional changes during guava fruit ripening. Food Chemistry, 80: 557-563.
4. Lin, Z.F., Li, S.S., Zhang, D.L., Lui, S.X., Li, Y.B., Li, Z.G. and Chen, M.D. (1988). The changes in oxidation and per oxidation in post-harvest litchi fruits. Acta Bot Sin, 30: 383-387.

5. Mahajan, B.V.C., Sharma, S.R. and Dhall, R.K. (2009). Optimization of storage temperature for maintaining quality of guava. Journal of Food Science Technology, 46(6): 604-605.

6. Reyes, M.U. and Paull, R.E. (1995). Effect of storage temperature and ethylene treatment on guava Psidium guajava fruit ripening. Post harvest Biology and Technology, 6: 357-365.

7. Singh, G., (2007). Recent development in production of guava. Acta Horticulture, 735: 161-176.

8. Singh, U.B. and Mohammed, S. (1997). Comparative efficiency of wax emulsion and rice starch on post-harvest shelf life of fully - ripe guava fruits. Journal of Food Science Technology, 34: 519-522.

9. Singh, S.P. and Pal, R.K., (2007). Controlled atmosphere storage of guava (Psidium guajava) fruit. Post harvest Biology and Technology, 47: 296-306.

10. Singh, S.P. and Pal, R.K., (2009). Ionizing radiation treatment to improve life and maintain quality of fresh guava of fresh guava fruit. Radiation Physics and Chemistry, 78: 135-140.

11. Wijewardane, R.M.N.A. and Guleria, S.P.S. (2009). Effect of Post harvest coating treatments on apple storage quality. Journal of Food Science Technology, 46 (6): 549553.

\section{Received: June, 2016 Revised: September, 2016 Accepted: December 2016}

